\title{
Investigation on the Thermal Stability of Refined Palm Oil Produced from Membrane-Based Refining Technique
}

\author{
W.J. Lau ${ }^{\mathrm{a},{ }^{\star}}$, A.F. Ismail ${ }^{\mathrm{a},{ }^{\star}}$, M. Razis ${ }^{\mathrm{a}}$, B.C. Ng${ }^{\mathrm{a}}$, P.S. Goh ${ }^{\mathrm{a}}$, R.A. Latip ${ }^{\mathrm{b}}$ and N.H. Othman ${ }^{\mathrm{b}}$ \\ ${ }^{a}$ Advanced Membrane Technology Research Centre (AMTEC), Universiti Teknologi Malaysia, 81310 Skudai, \\ Johor, Malaysia \\ ${ }^{b}$ Sime Darby R\&D Centre Downstream, Lot 2664, Jalan Pulau Carey, 42960 Pulau Carey, Selangor, \\ Malaysia
}

\begin{abstract}
The main objective of this work is to study the heat stability of refined palm oil produced from membranebased refining process. Two novel routes of refining process have been proposed in which the first one was to integrate conventional refining process with ultrafiltration (UF) membrane technology while the second route was based on the integration between conventional refining process and UF membrane-solvent extraction process. The results revealed that the two novel refining routes showed improvement on free fatty acid (FFA) stability compared with the conventional technique throughout 5-day studied period. With respect to peroxide value (PV), it is found that only the first proposed route showed very similar increasing trend with the conventional refining process. In addition to this, it is also found that the two refining routes which were operated at $260^{\circ} \mathrm{C}$ showed slightly better colour stability in comparison to conventionally-produced oil.
\end{abstract}

Keywords: Membrane technology, solvent extraction, crude palm oil, free fatty acid, phospholipids.

\section{INTRODUCTION}

Over the last 15 years, there are quite a number of research works reporting the alternative methods for vegetable oil refining process [1-4]. Of the methods being evaluated as alternative process, membranebased separation is found to be the most suitable solution to overcome the drawbacks associated with conventional refining process and show the great potential to be commercialized [5-9].

It is generally agreed that the adoption of membrane technology into the refining process could significantly reduce the use of chemicals and the cost of utility, leading to little amount of effluent discharged. It has been evidenced that without the presence of additional chemical during degumming process, membrane is found to be very useful in phospholipids separation and the efficiency of its separation depends on the membrane pore size selected [10-12]. Unlike phospholipids which can form micelles in nonaqueous environment, separating free fatty acid (FFA) from triglycerides (TGs) using membrane-based technology is found to be very challenging. This is because of the very similar molecular weights of these two components. Current technology has limitation to produce a membrane with very precise pore size that can act as barrier to retain TG while allowing FFA to

*Address correspondence to these authors at the Advanced Membrane Technology Research Centre (AMTEC), Universiti Teknologi Malaysia, 81310 Skudai, Johor, Malaysia; Tel: +6 07553 5926;

E-mails: Iwoeijye@utm.my, afauzi@utm.my permeate. In view of this, membrane technology integrated with solvent extraction process has been proposed by Cheryan and his research team $[13,14]$ in 1990s. The process proposed used alcohol-based solvent to extract FFA from the oil followed by nanofiltration process to recover the alcohol from the solvent rich in FFA.

It is found that the number of relevant research works published has showed no sign of decreasing in the recent years. Many researchers have continued to make new attempts to prove the feasibility of membrane technology as alternative solution for existing refining technology. Although membrane technology showed great potential in refining process, the complete implementation of this technology in industrial scale still needs more efforts and time [15]. For the time being, it would be great to know if membrane technology could be integrated with existing refining process in the production of better quality of refined oil. It is generally agreed that resistance to oxidative degradation during storage is an important issue for the successful development of alternative refining process. The oxidation of unsaturated esters in cooking oil during storage is a main concern to many people as it may impair oil quality and subsequently become a threat to human health.

The objective of this work is to study the thermal stability of refined palm oil produced from three different refining routes i.e. (a) conventional physical steam refining, (b) conventional refining integrated with membrane technology and (c) conventional refining 
integrated with membrane-solvent extraction technology. To our best knowledge, there is so far no research work reporting the stability of refined oil properties produced using membrane-based technology. Most of the relevant works only documented the performances of membranes in either degumming or deacidification process without taking into consideration the possibility of integrating membrane technology with existing refining process to produce refined oils of better stability. In this work, all the oil samples were analysed with respect to FFA, PV and colour over a period of 5 days and it is expected that results would lead to a better understanding of the quality of oils produced from membrane-based separation.

\section{MATERIALS AND METHODS}

\section{Materials}

Commercial polyvinylidene fluoride (PVDF) pellets (Kynar $^{\circledR}$ 740) purchased from Arkema Inc., USA was used as main component in UF membrane formation. The reason of choosing this polymer in membrane preparation is mainly due to its excellent resistance against thermal and chemical attacks. Other chemicals used in this study for oil sample analysis were purchased in analytical grade and used as received without further treatment.

\section{Crude Palm Oil Refining Process}

Figure 1 shows the complete flow sheet of three different routes of refining process conducted in this work. The conventional physical refining process involved three main stages of processing, i.e. (a) gums removal with the addition of $0.01-0.04 \%$ phosphoric acid into crude palm oil (CPO) under $80-85^{\circ} \mathrm{C}$ and vacuum condition, (b) pigments removal using $1 \%$ bentonite bleaching earth under $95-100^{\circ} \mathrm{C}$ and vacuum condition and (c) deodorization (together with deacidification) through steam refining under $260^{\circ} \mathrm{C}$ and vacuum condition to produce refined, bleached and deodorized palm oil (RBDPO). In this study, two novel refining routes were proposed with the objectives of removing phospholipids in the absence of chemicals and reducing the FFA content through solvent extraction method. The final oil samples produced from these two proposed routes are referred to as $\mathrm{M}$ RBDPO and M-SE-RBDPO, respectively. $M$ is designated to membrane while $S E$ is for solvent extraction. Besides different routes of refining process, the effect of operating temperature in deodorisation process on the stability of refined oil was also investigated. In order to study the possibility of refining CPO using novel refining route at lower energy consumption, the operating temperature of deodorization process was reduced from typical 260 to $240^{\circ} \mathrm{C}$.

\section{Membrane Degumming}

In the first proposed refining route, the conventional degumming process using phosphoric acid has been eliminated and replaced with membrane separation process. The detailed procedures on the hollow fiber fabrication can be found in our earlier publication [16]. During this experiment, a customized stainless-steel permeation cell having a diameter of $6.5 \mathrm{~cm}$ and height of $33 \mathrm{~cm}$ was used to conduct the degumming process. A U-tube shaped hollow fiber module (average pore diameter $-24 \mathrm{~nm}$ ) which consisted of 60 fibers in 30 $\mathrm{cm}$ long (equivalent to $735 \mathrm{~cm}^{2}$ effective area) was housed within the cell of $1050 \mathrm{~mL}$ capacity. The transmembrane pressure and temperature of refining process were maintained at 2 bar and $50 \pm 1^{\circ} \mathrm{C}$, respectively throughout the experiments. The degummed palm oil collected from the downstream side of the cell through $1 / 2$ " stainless-steel tubing was then used for the subsequent refining process as shown in Figure 1.

\section{Deacidification using Solvent Extraction}

In the second proposed refining route, methanol (Sigma Aldrich) was selected as the solvent mainly due to its high selectivity to FFA compared with other types of alcohol $[17,18]$. Prior to the solvent extraction, the CPO was first degummed using PVDF UF membrane as explained in the first proposed refining route. An optimal ratio of $1.8 \mathrm{~g}$ of methanol per gram of oil was employed in an effort to maximize the amount of FFA extracted. The mixture was then stirred for $30 \mathrm{~min}$ in $400 \mathrm{rpm}$ at $50 \pm 1{ }^{\circ} \mathrm{C}$ before transferring to the separator funnel for settling. The oil phase at the bottom of the funnel was collected after $30 \mathrm{~min}$ of settling time and subjected to the subsequent refining process as shown in Figure 1.

\section{Analytical Methods}

The stability of refined oil properties as a function of time was estimated according to American Oil Chemists' Society (AOCS) method (http://www.aocs. org/Methods/). Free fatty acid (FFA), phosphorus, peroxide value $(\mathrm{PV})$ and anisidine value $(\mathrm{AnV})$ in the oil 


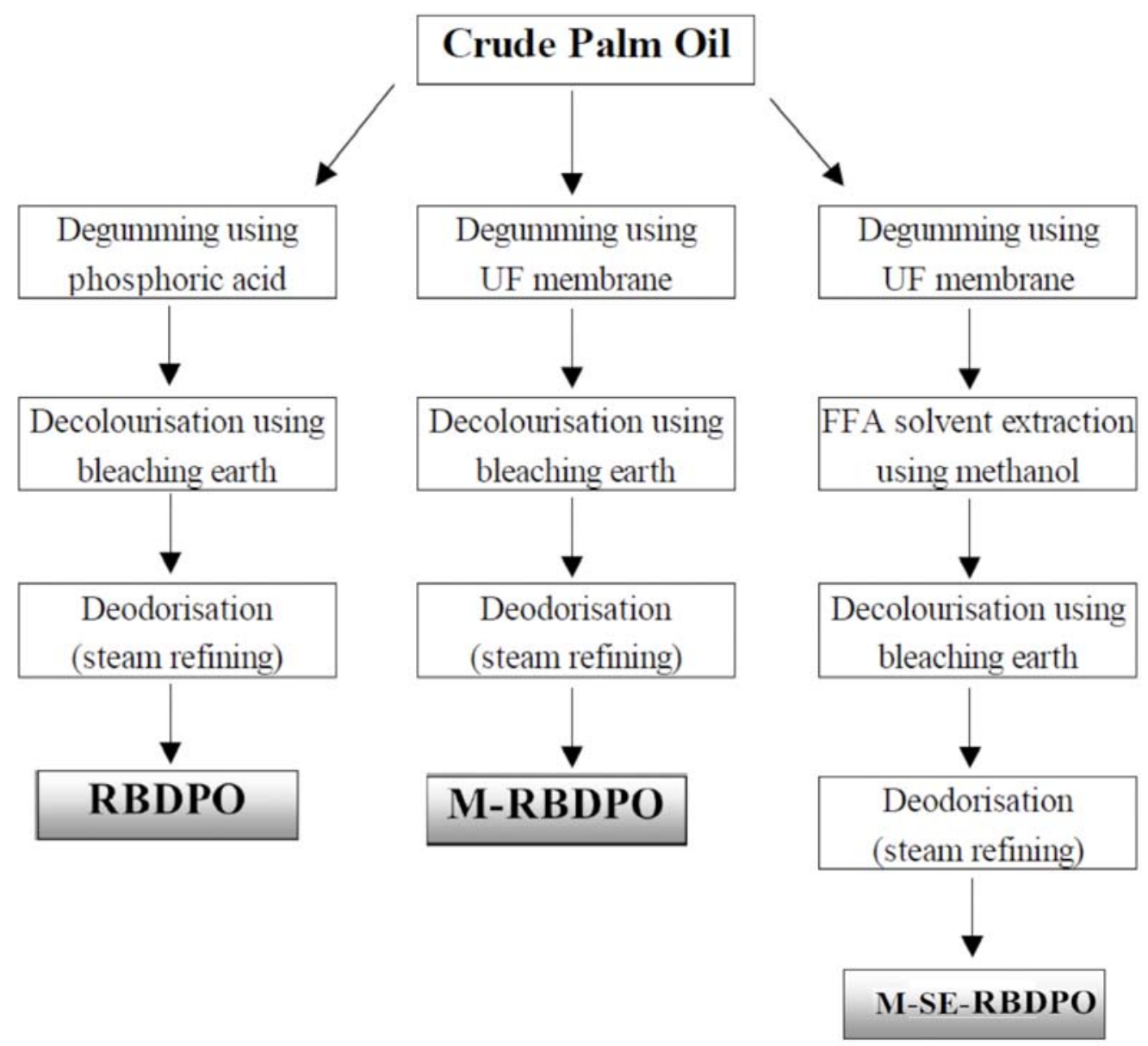

Figure 1: Flow sheet of crude palm oil refining process using different refining techniques.

samples were determined using AOCS method - Cd 3d-63, Ca 12-55 and $\mathrm{Cd} 8 \mathrm{~b}-90$ and $\mathrm{Cd}$ 18-19, respectively. The colour of oil samples was determined using Lovibond Tintometer (model F). The colour was matched using colour racks of red $(\mathrm{R})$ and yellow $(\mathrm{Y})$. Thermal stability test was conducted using accelerated test method (industrially acceptable) by adding $1 \%$ pure water into the oil sample and kept in oven at $90^{\circ} \mathrm{C}$ to speed up the oxidation process. The properties of the oil were determined daily for 5 consecutive days. The accelerated heat stability of M-RBDPO and M-SERBDPO was then compared with the RBDPO produced from conventional refining technique.

\section{RESULTS AND DISCUSSION}

\section{Membrane Filtration and Solvent Extraction}

Table 1 shows the properties of oil refined using membrane-based technology with and without integration of solvent extraction method. As can be seen from the table, there was a significant reduction in the phosphorus content of membrane-based refining process in comparison to the crude palm oil. The content of FFA, however, was found to be reduced only with the use of methanol in solvent extraction. In the work of Raman et al. [13], it is also showed that partial separation could be accomplished when solvent was used. Besides showing remarkable reduction in phosphorus and FFA (only for membrane process integrated with solvent extraction method), it is also found that membrane-based refining process was able to remove the impurities and partially reduce moisture and colour in the crude palm oil. It must be pointed out that carotene which is a precursor to vitamin A was further concentrated after membrane filtration process and this indicated the capability of membrane in producing the oils of higher content of nutrients. Similar results were also reported by lyuke et al. [10] in which the membrane treatment process did not affect the carotene content of permeate sample.

\section{Free Fatty Acid (FFA)}

Figure 2 presents the FFA stability of refined oil as a function of day for two novel refining processes. The results obtained from the conventional physical refining 
Table 1: The Properties of Oil Pre-Treated Using Membrane (M-CPO) and Membrane-Solvent Extraction Technology (M-SE-CPO)

\begin{tabular}{|c|c|c|c|}
\hline \multirow{2}{*}{ Analysis } & \multirow{2}{*}{${ }^{\mathrm{a}} \mathrm{CPO}$} & \multicolumn{2}{|c|}{ Pre-treatment Process } \\
\hline & & Ultrafiltrated oil ( $\left.{ }^{\mathrm{b}} \mathrm{M}-\mathrm{CPO}\right)$ & Ultrafiltrated+solvent extracted oil ( ${ }^{\mathrm{C}} \mathrm{M}$-SE-CPO) \\
\hline FFA, \% & 3.63 & 3.66 & 1.76 \\
\hline Phosphorus, ppm & 11.88 & 3.26 & 4.44 \\
\hline Moisture, \% & 0.42 & 0.24 & 0.19 \\
\hline $\mathrm{PV}, \mathrm{meq} / \mathrm{kg}$ & Nil & Nil & 4.51 \\
\hline AnV & 4.58 & 4.83 & 5.17 \\
\hline Impurities, \% & 0.021 & 0.003 & 0.004 \\
\hline Carotene, ppm & 591.00 & 620.00 & 654.00 \\
\hline Colour 1" cell & 27R 27Y & 21R 21Y & 23R 23Y \\
\hline
\end{tabular}

${ }^{a} \mathrm{CPO}=$ Crude palm oil.

${ }^{\mathrm{b}} \mathrm{M}-\mathrm{CPO}=$ Degumming of CPO using UF membrane technology. The average oil flux of membrane was $2.07 \mathrm{~kg} / \mathrm{m}^{2} . \mathrm{hr}$ at $2 \mathrm{bar}$ and $50^{\circ} \mathrm{C}$.

${ }^{\mathrm{C}} \mathrm{M}-\mathrm{SE}-\mathrm{CPO}=$ Degumming and deacidification of $\mathrm{CPO}$ using membrane and solvent extraction technology.

process have also been included in this figure for comparison. As can be clearly seen, all oil samples showed no sign of FFA after the refining process regardless of refining route. In comparison to the FFA of RBDPO sample which reached $0.38 \%$ after 5 days of study, the FFA content in M-RBDPO and M-SERBDPO samples remained almost the same throughout the studied period. These findings showed a positive sign of oil samples with good stability. It must be pointed out that the decrease in operating temperature in deodorisation process from 260 to $240^{\circ} \mathrm{C}$ did not negatively affect the quantities of FFA as these oil samples exhibited very similar results with respect to FFA content. From the viewpoint of industry, any reduction in operating temperature could contribute greatly to energy savings, considering the huge quantity of CPO needed to be refined daily [19].

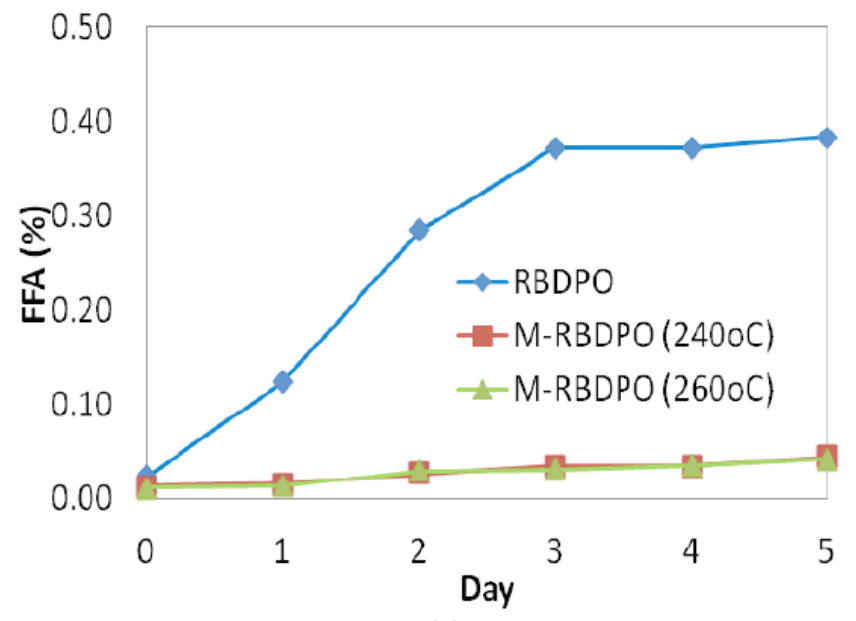

(a)

\section{Peroxide Value (PV)}

Figure 3 shows the change of PV of oil samples produced from different refining process in 5 days. As shown, the initial PV of oil samples was the same regardless of refining process. Although PV is not one of the criteria under Palm Oil Refiners Association of Malaysia (PORAM) (http://www.poram.org.my) standard specification of processed palm oil, a refined oil of good quality usually needs to have less than 1.0 $\mathrm{meq} / \mathrm{kg}$ PV after refining. It is recorded that the PV of RBDPO was increased steadily and reached 20.6 $\mathrm{meq} / \mathrm{kg}$ at Day 5 . Similar increasing trend was also observed in the oil samples refined using novel technique. Among the samples tested, the PV of $\mathrm{M}$ RBDPO refined at $260^{\circ} \mathrm{C}$ was the lowest one. Its PV of $19 \mathrm{meq} / \mathrm{kg}$ was slightly lower than that of conventional

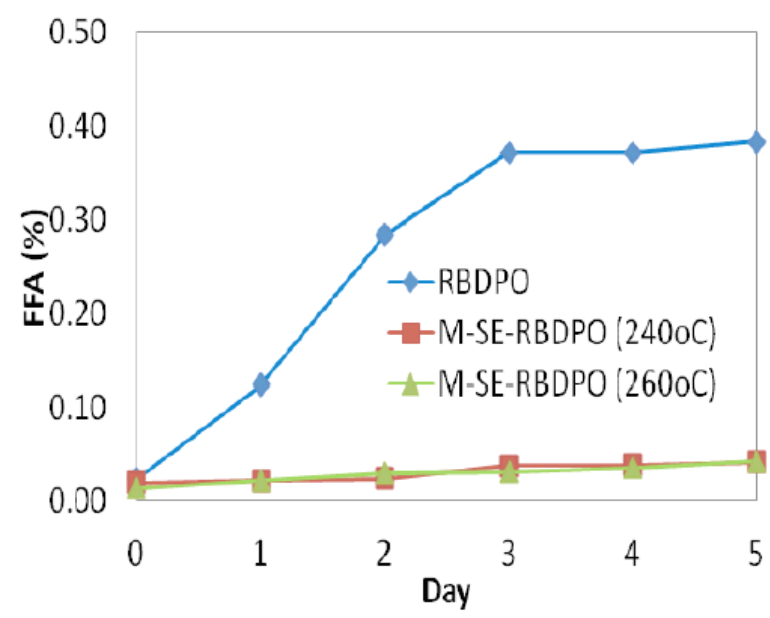

(b)

Figure 2: FFA stability of refined oil as a function of day, (a) M-RBDPO and (b) M-SE-RBDPO (Standard specification for RBDPO (http://www.poram.org.my): $0.1 \%$ max. FFA). 


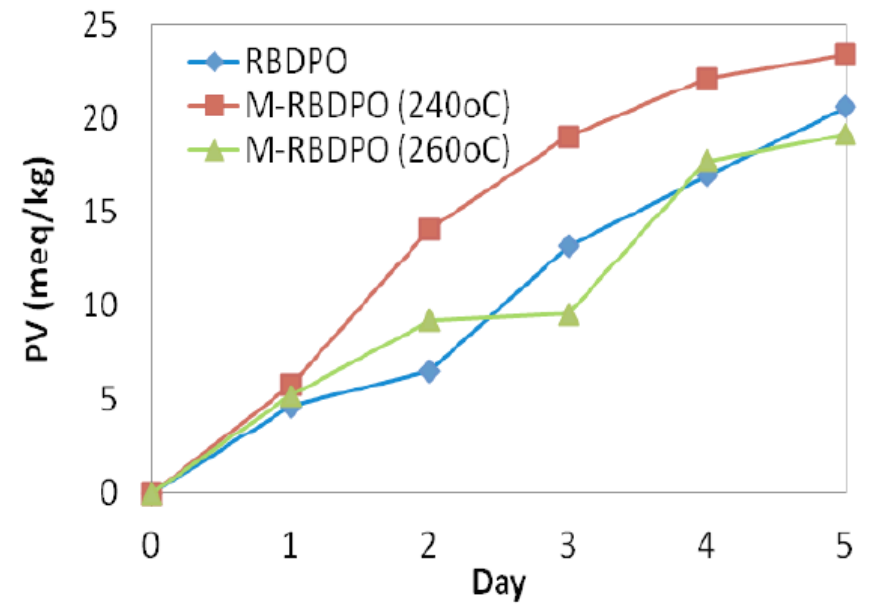

(a)

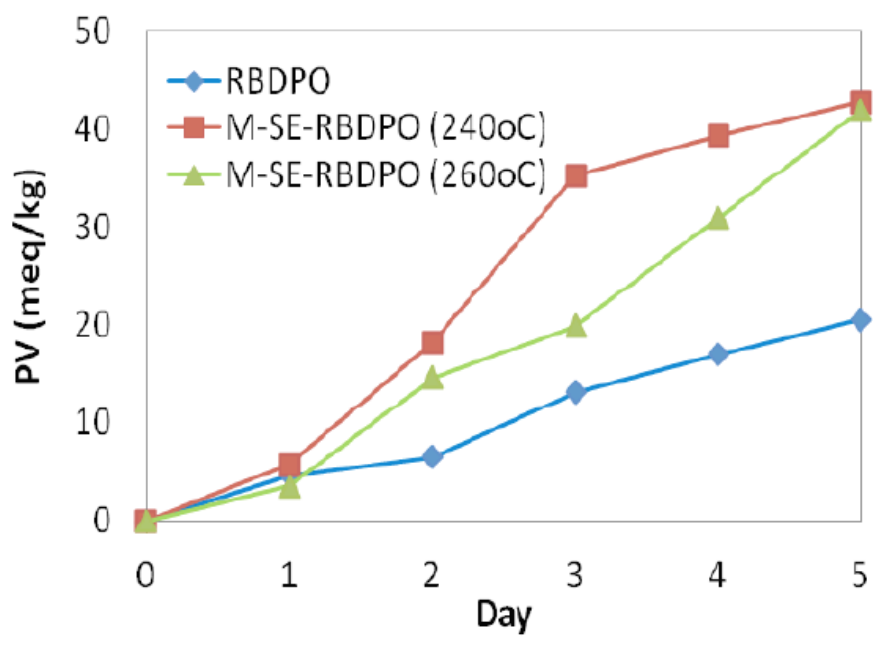

(b)

Figure 3: PV stability of refined oil as a function of day, (a) M-RBDPO and (b) M-SE-RBDPO.

refining process. There is a reason to believe that instead of using phosphoric acid to remove phospholipids (as widely adopted in conventional refining process), the use of membrane technology could minimize the loss of carotene and provide greater resistance to oxidative deterioration, extending its shelf-life $[20,21]$. Although M-SE-RBDPO showed very stable with respect to FFA content, its PV stability was not as good as M-RBDPO. The PV of M-SE-RBDPO recorded was more than double the value of RBDPO, reaching 42.8 and 42.0 for M-SE-RBDPO $\left(240^{\circ} \mathrm{C}\right)$ and M-SE-RBDPO $\left(260^{\circ} \mathrm{C}\right)$, respectively. The reduced PV stability as found in M-SE-RBDPO sample can be caused by the additional refining step required in the FFA extraction which increases the exposure time of oil

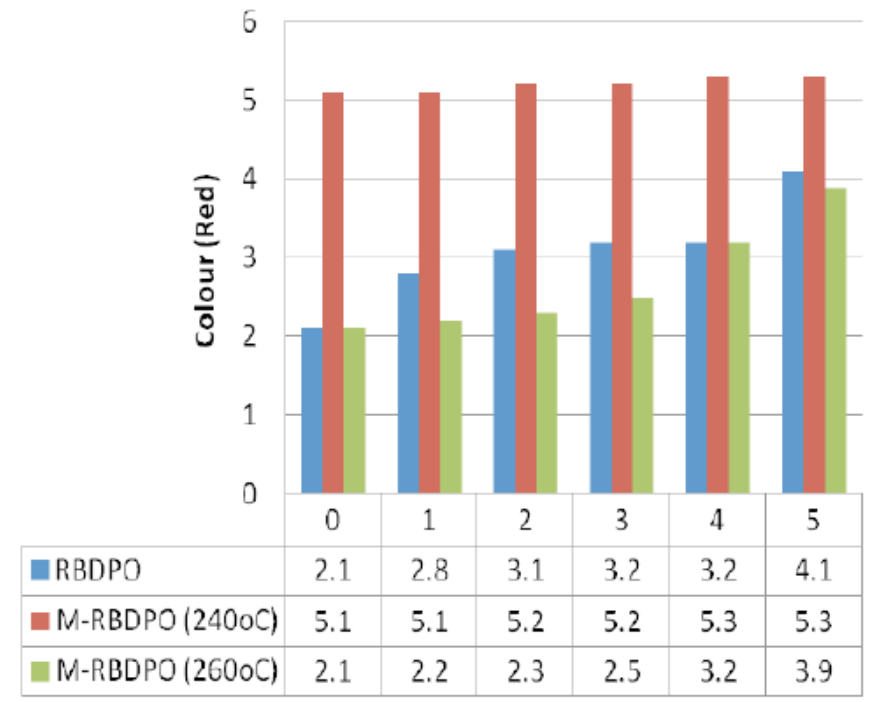

(a) sample to the surrounding air. Due to this, the addition of oxygen at or near the double bond of fatty acid chain might form unstable compounds which are generally designated as peroxides and further deteriorating the oil quality [19].

\section{Colour}

It is generally agreed that oxidation has a direct effect on the colour of oil. It has potential to develop coloured compounds of quinoid nature from the fatty acids and/or acylglycerols of the oils, darkening the oil refined. Figure 4 presents the effect of oxidation on the colour stability of oil produced from different refining routes. In industry, in order for the edible oil to be safe

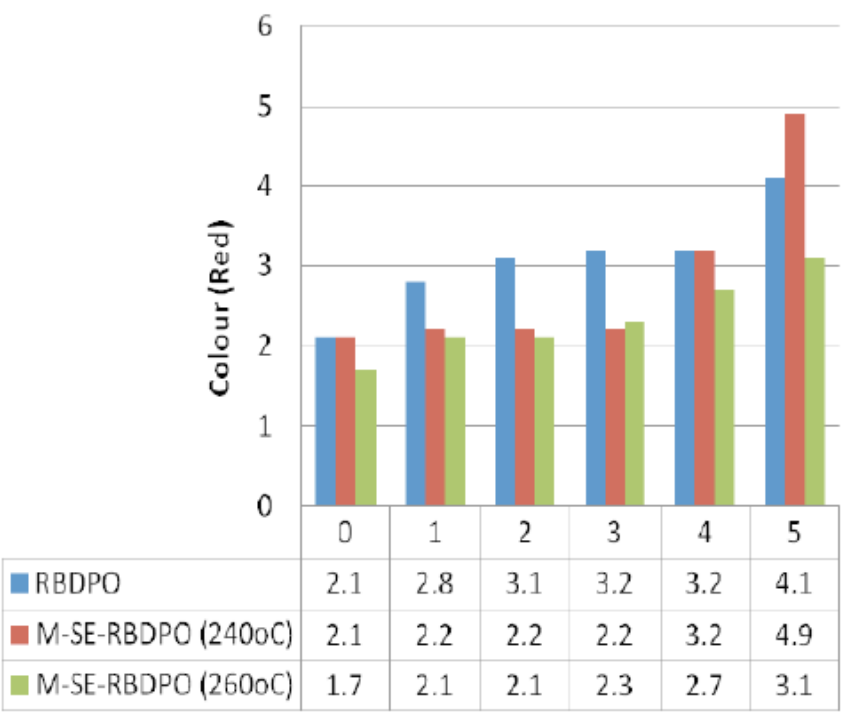

(b)

Figure 4: Change in colour of refined oil as a function of day, (a) M-RBDPO and (b) M-SE-RBDPO (Standard specification for RBDPO (http://www.poram.org.my): 3.0 max Red). 
for human consumption, the standard colour of RBDPO must be no more than 3.0 Red. As can be seen from the figure, all oil samples except M-RBDPO at $240^{\circ} \mathrm{C}$ fell within the acceptable range. The recorded red colour value of M-RBDPO $\left(240^{\circ} \mathrm{C}\right)$ was 5.1 at initial day and increased to 5.3 at Day 5. This revealed that operating temperature is very critical in ensuring the minimal red colour of the final refined oil product. Any reduction from the typical refining operating temperature $\left(260^{\circ} \mathrm{C}\right)$ would make the oil product failed to meet the standard colour of refined oil. Besides showing higher red colour value at the initial day, refining the crude vegetable oil at lower temperature also showed rapid development of red colour value as evidenced in M-SE-RBDPO $\left(240^{\circ} \mathrm{C}\right)$. With increasing the refining temperature from 240 to $260^{\circ} \mathrm{C}$, it is found that the red values of M-RBDPO and M-SE-RBDPO were significantly reduced. M-RBDPO $\left(260^{\circ} \mathrm{C}\right)$ sample showed $4.9 \%$ red colour reduction while M-SE-RBDPO $\left(260^{\circ} \mathrm{C}\right)$ displayed $24.4 \%$ colour reduction at the end of studied period. This indicated that the novel refining routes proposed somehow are able to produce similar oil standard with respect to colour, provided the refining temperature applied is the same as the one used for RBDPO process.

\section{CONCLUSIONS}

In this study, the process of refining crude palm oil using two novel refining routes has been successfully conducted. The properties of their thermal stability with respect to FFA, PV and colour have been compared with the conventional physical steam refining process. It is found that the palm oil refined using the proposed refining routes demonstrated much better FFA stability and showed insignificant increases on FFA content throughout the 5-day studied period in comparison to the conventionally-produced oil. With respect to PV, results indicated that only the sample of M-RBDPO refined at $260^{\circ} \mathrm{C}$ was found to display very similar increasing trend with the conventional refining process. The rest of the novel refining processes proposed tended to show greater extent of PV increase. Results also revealed that the oil samples refined at $240^{\circ} \mathrm{C}$ using novel refining routes were tended to develop higher red colour value in short period of time compared with the oil samples refined at $260^{\circ} \mathrm{C}$. Only the oil samples refined at typical operating temperature were able to show red colour values lower than that of conventional refining process. Based on these findings, it can be concluded that the stability of M-RBDPO samples refined at $260^{\circ} \mathrm{C}$ is comparable with the oil properties produced by the conventional refining.
Further investigation however is still needed to examine the feasibility of proposed refining route with respect to economic aspect in edible oil production.

\section{REFERENCES}

[1] Rafe A, Razavi SMA. Water and hexane permeate flux through UF polysulfone amide membrane. Desalination 2009; 236: 39-45.

http://dx.doi.org/10.1016/i.desal.2007.10.048

[2] Dunford NT, King JW. Thermal gradient deacidification of crude rice bran oil utilizing supercritical carbon dioxide. J Am Oil Chem Soc 2001; 78: 121-5. http://dx.doi.org/10.1007/s11746-001-0231-1

[3] Sengupta R, Bhattacharyya DK. Enzymatic deacidification of rice bran oils of varying acidity. J Oil Technol Assoc India 1996; 28: 17-21.

[4] Subramanian R, Nakajima M, Kawakatsu T. Processing of vegetable oils using polymeric composite membranes. J Food Eng 1998; 38: 41-56.

http://dx.doi.org/10.1016/S0260-8774(98)00106-X

[5] Manjula S, Subramanian R. Simultaneous degumming, dewaxing and decolorizing crude rice bran oil using nonporous membranes. Sep Purif Technol 2009; 66: 223-8. http://dx.doi.org/10.1016/j.seppur.2009.01.004

[6] De Morais Coutinho C, Chiu MC, Basso RC, Badan Ribeiro AP, Goncalves LAG, Viotto LA. State of art of the application of membrane technology to vegetable oils:A review. Food Res Int 2009; 42: 536-50.

http://dx.doi.org/10.1016/j.foodres.2009.02.010

[7] Hafidi A, Pioch D, Ajana, H. Membrane-based simultaneous degumming and deacidification of vegetable oils. Innov Food Sci Emerg Technol 2005; 6: 203-12. http://dx.doi.org/10.1016/j.ifset.2004.12.001

[8] Lin L, Rhee KC, Koseoglu SS. Bench-scale membrane degumming of crude vegetable oil: process optimization. J Membr Sci 1997; 134: 101-8.

http://dx.doi.org/10.1016/S0376-7388(97)00098-7

[9] Ochoa N, Pagliero C, Marchese, J, Mattea, M. Ultrafiltration of vegetable oils Degumming by polymeric membranes, Sep Purif Technol 2001; 22-23: 417-22. http://dx.doi.org/10.1016/S1383-5866(00)00178-7

[10] lyuke SE, Ahmadun F, Majid RA. Process Intensification of membrane system for crude palm oil pretreatment. J Food Process Eng 2004; 27 : 476-96. http://dx.doi.org/10.1111/j.1745-4530.2004.00469.x

[11] Pagliero C, Ochoa N, Marchese J, Mattea M. Vegetable oil degumming with polyimide and polyvinylidenefluoride ultrafiltration membranes. J Chem Technol Biotechnol 2004; 79: 148-52. http://dx.doi.org/10.1002/jctb.951

[12] Kim IC, Kim JH, Lee KH, Tak TM. Phospholipids separation (degumming) from crude vegetable oil by polyimide ultrafiltration membrane. J Membr Sci 2002; 205: 113-23. http://dx.doi.org/10.1016/S0376-7388(02)00070-4

[13] Raman LP, Rajagopalan N, Cheryan M. Membrane technology in vegetable oils processing. Oils Fats Int 1994; 10(6): 32-8.

[14] Kale V, Katikaneni, SPR, Cheryan M. Deacidifying rice bran oil by solvent extraction and membrane technology. J Am Oil Chem Soc 1999; 76: 723-7.

http://dx.doi.org/10.1007/s11746-999-0166-4

[15] Badan Ribeiro AP Bei N, Guaraldo Goncalves LA, Cunha Petrus JC, Viotto LA. The optimisation of soybean oil degumming on a pilot plant scale using a ceramic membrane. J Food Eng 2008; 87: 514-21.

http://dx.doi.org/10.1016/j.jfoodeng.2008.01.003 
[16] Lau WJ, Ismail AF. Theoretical studies on the morphological and electrical properties of blended PES/SPEEK nanofiltration membranes using different sulfonation degree of SPEEK. J Membr Sci 2009; 334: 30-42.

http://dx.doi.org/10.1016/j.memsci.2009.02.012

[17] Shah KJ, Venkatesan TK. Aqueous isopropyl alcohol for extraction of free fatty acids from oils. J Am Oil Chem Soc 1989; 66: 783-7.

http://dx.doi.org/10.1007/BF02653668

[18] Raman LP, Cheryan M, Rajagopalan N. Deacidification of soybean oil by membrane technology. J Am Oil Chem Soc 1996; 73: 219-24.

http://dx.doi.org/10.1007/BF02523898
[19] Shahidi F. Bailey's Industrial Oil and Fat Products, $6^{\text {th }}$ ed., New Jersey: John Wiley \& Sons, Inc 2004.

[20] Navarro-Garcia G, Bringas-Alvarado L, Pacheco-Aguilar R, Ortega-Garcia J. Oxidative resistance, carotenes, tocopherols and lipid profile of liver oil of the ray Rhinoptera steindechneri. J Food Comp Anal 2004; 17: 699-706. http://dx.doi.org/10.1016/j.jfca.2004.01.004

[21] Wanasundara UN, Shahidi F, Amarowicz R. Effect of processing on constituents and oxidative of marine oils. $J$ Food Lipids 1998; 5: 29-41.

http://dx.doi.org/10.1111/j.1745-4522.1998.tb00105.x 